\title{
Article \\ Bone Lengthening with a Motorized Intramedullary Nail in 34 Patients with Posttraumatic Limb Length Discrepancies
}

\author{
Maxime Teulières ${ }^{1}$, Tristan Langlais ${ }^{1}\left[\mathbb{C}\right.$, Jérôme Sales de Gauzy ${ }^{1}$, Jan Duedal Rölfing ${ }^{2} \mathbb{C}$ and Franck Accadbled ${ }^{1, *}$ \\ 1 Department of Pediatric Orthopaedics, CHU de Toulouse, 31300 Toulouse, France; \\ maxime.teulieres@gmail.com (M.T.); tristanlanglais@yahoo.fr (T.L.); salesdegauzy.j@chu-toulouse.fr (J.S.d.G.) \\ 2 Children's Orthopaedics and Reconstruction, Aarhus University Hospital, 8200 Aarhus, Denmark; \\ jan.roelfing@rm.dk \\ * Correspondence: accadbled.f@chu-toulouse.fr
}

Citation: Teulières, M.; Langlais, T.; de Gauzy, J.S.; Rölfing, J.D.;

Accadbled, F. Bone Lengthening with a Motorized Intramedullary Nail in 34 Patients with Posttraumatic Limb Length Discrepancies. J. Clin. Med. 2021, 10, 2393. https://doi.org/ $10.3390 /$ jcm10112393

Academic Editor: Rocco Papalia

Received: 2 May 2021

Accepted: 26 May 2021

Published: 28 May 2021

Publisher's Note: MDPI stays neutral with regard to jurisdictional claims in published maps and institutional affiliations.

Copyright: (c) 2021 by the authors. Licensee MDPI, Basel, Switzerland. This article is an open access article distributed under the terms and conditions of the Creative Commons Attribution (CC BY) license (https:/ / creativecommons.org/licenses/by/ $4.0 /)$.

\begin{abstract}
The Fitbone ${ }^{\circledR}$ motorized nail system has been used to correct limb length discrepancies (LLD) for several years. This study focuses on its application in posttraumatic limb lengthening surgery, its outcome and challenges. Materials and methods: A prospective, single center study was conducted between 2010 and 2019 in patients treated with motorized lengthening nails. The inclusion criteria were symptomatic LLD of $20 \mathrm{~mm}$ or more. An imaging analysis was done using TraumaCad ${ }^{\circledR}$ software (Brainlab AG, Munich, Germany) to compare frontal alignment angles and limb length discrepancy (LLD) on preoperative and latest follow-up radiographs of the lower limbs. Results: Thirty-four patients were included with a mean age of $28.8 \pm 9.7$ years, a mean follow-up of $27.8 \pm 13$ months and a mean hospital stay of $4.4 \pm 1.7$ days. The mean LLD was $44 \pm 18 \mathrm{~mm}$ in 29 femoral and $32 \pm 8 \mathrm{~mm}$ in 4 tibial cases, which was reduced to less than $10 \mathrm{~mm}$ in 25/34 (74\%) patients. The mean healing index was $84.6 \pm 62.5$ days $/ \mathrm{cm}$ for femurs and $92 \pm 38.6$ days $/ \mathrm{cm}$ for tibias. The mean time to resume full weight-bearing without walking aids was 226 days \pm 133 . There was no significant difference between preoperative and final follow-up alignment angles and range of motion. The mechanical lateral distal femoral angle (mLDFA) was corrected in the subgroup of 10 LLD patients with varus deformity of the femur (preoperative $95.7^{\circ}( \pm 5.0)$ vs. postoperative $\left.91.5^{\circ}( \pm 3.4), p=0.008\right)$. According to Paley's classification, there were 14 problems, 10 obstacles and 2 complications. Discussion: Six instances of locking screw pull out, often requiring reoperation, raise the question of whether a more systematic use of blocking screws that provide greater stability might be indicated. Lack of compliance can lead to poor outcomes, patient selection in posttraumatic LLD patients is therefore important. Conclusion: Limb lengthening with a motorized lengthening nail for posttraumatic LLD is a relatively safe and reliable procedure. Full patient compliance is crucial. In-depth knowledge of lengthening and deformity correction techniques is essential to prevent and manage complications.
\end{abstract}

Keywords: limb lengthening; bone lengthening; limb length discrepancy; LLD; MAD; mLDFA; MPTA; intramedullary lengthening nail; FITBONE; posttraumatic; fracture; complications

\section{Introduction}

Lower extremity long bone fractures can cause limb length discrepancies (LLD) in case of unsuccessful reduction, fixation failure, or secondary displacement [1-3]. LLD after intramedullary nailing for femoral shaft fractures has been reported to affect up to $43 \%$ of patients, especially in complex and communitive fractures [4]. Growth plate injuries in skeletally immature individuals can also result in LLD $[5,6]$.

LLD can cause limping, back pain, and secondary degenerative changes, i.e., osteoarthritis. Mild LLD, i.e., less than $2 \mathrm{~cm}$, can most often be satisfactorily treated with a shoe raise. However, marked LLD of more than 2-2.5 cm may warrant limb lengthening surgery. Historically, external fixation was the preferred lengthening method [7]. However, 
technical breakthroughs have resulted in reliable motorized intramedullary lengthening nails, such as FITBONE ${ }^{\circledR}$ (Orthofix, Lewisville, TX, USA) and PRECICE ${ }^{\circledR}$ (NuVasive, Aliso Viejo, CA, USA) [7-12]. Intramedullary lengthening nails with full weightbearing capability allowing faster postoperative rehabilitation and simultaneous bilateral lengthenings are the frontier and logical next step of the evolution of these devices.

Compared with idiopathic LLD, posttraumatic patients are more likely to sustain complications when undergoing lengthening surgery due to pre-existing complicating factors, e.g., scare tissue, joint stiffness, dormant infection, skin issues, etc. [7,8]. This study investigates bone lengthening in posttraumatic patients with the FITBONE ${ }^{\circledR}$ intramedullary nailing system at Toulouse University Hospital in France. Patient characteristics, lengthening modalities, radiographic analyses of the achieved lengthening and axial deformity correction, as well as complications are presented.

\section{Materials and Methods}

In this prospective, single center, single surgeon case series, 34 posttraumatic limb lengthening patients (femoral: 30, tibial: 4) were included from January 2010 until April 2019. Patient selection was based on the following inclusion criteria: patients with a symptomatic, posttraumatic LLD of $20 \mathrm{~mm}$ or more.

Causes of femoral LLD were 10 shaft fractures treated with intramedullary nails, 6 distal fractures (4 plates, 2 external fixators) and 3 proximal femoral fractures ( 2 intertrochanteric nails, 1 dynamic hip screw). Ten LLD cases were the result of trauma to the immature skeleton, among which 6 were due to physeal injuries. Causes of tibial LLD were 2 shaft fractures, 1 pilon fracture and 1 distal growth plate injury. One functional LLD was included in our cohort. The patient fell from a horse causing a Tile type $\mathrm{C}$ pelvic fracture with hemipelvic dislocation despite fracture fixation (Table 1).

Table 1. Anatomical site of the injuries causing posttraumatic limb length discrepancies.

\begin{tabular}{ccc}
\hline & & $N=\mathbf{3 4}$ \\
\hline \multirow{2}{*}{ Immature skeleton } & Femur & 10 \\
& Tibia & 2 \\
& Femur & 3 \\
Mature skeleton & Proximal & 10 \\
& Shaft & 6 \\
& Distal & 2 \\
Functional LLD & Tibia & 1 \\
\hline
\end{tabular}

In 15 cases, trauma was the result of a road traffic accident. Nine cases involved a motorcycle. Two gunshot injury patients were included in our cohort and 10/34 (29\%) were open fractures. Gustilo Anderson classification of the open fractures was not possible, because multiple of the patients were referred several years after the initial trauma.

\subsection{Surgical Technique}

Preoperative planning followed the reverse planning method described by Baumgart using anteroposterior (AP), full-length long standing radiographs and the TraumaCad ${ }^{\circledR}$ software (Brainlab AG, Munich, Germany) [13]. Accordingly, the osteotomy site and the position of the implant were mapped out to achieve the desired corrections. Implant insertion was either antegrade or retrograde for femoral lengthening and antegrade for tibial cases. The FITBONE ${ }^{\circledR}$ TAA (Telescope Active Actuator) mechatronic implant also allowing was used in the 30 cases, while the SAA (Sliding Active Actuator) also allowing bone transport was used in 4 femoral cases. The TAA implant is available in 9, 11, and $13 \mathrm{~mm}$ diameters and is capable of lengthening up to $8 \mathrm{~cm}$ without recharging of the nail. In accordance with the instructions for use, no healthy, open growth plates were crossed by the lengthening nail. 
Anteroposterior or mediolateral blocking screws were used if needed to correct deformities and/or further stabilize the implant [14-16].

Surgical procedure: The patient was positioned supine on a radiolucent operating table fitted with a plexiglass plate and a metal grid to assess the mechanical axis of the limb intraoperatively. Steinman pins positioned horizontally on each side of the osteotomy site (posterior femoral condyle and lesser trochanter for femoral lengthening) helped to prevent rotational malalignment or accurately correct rotational deformity if indicated. A percutaneous, multiple drill hole osteotomy was performed under fluoroscopic guidance before reaming in order to minimize the risk of fat embolism and to increase the amount of reaming debris at the osteotomy site [17]. According to the preoperative plan, Kirschner wires were inserted at standard entry points for ante- or retrograde nailing. This was used to insert a cannula for rigid intramedullary reaming under fluoroscopic guidance. After implantation, the nail was connected to a subcutaneously implanted receiver and the motor was tested under sterile conditions at the end of the procedure. A single shot nerve block was applied in all femoral, but none of the tibial cases.

\subsection{Postoperative Follow-Up}

Lengthening started on postoperative day 3 for femurs and 5 for tibias. Additional days of latency were added in patients 40 years and older, with the presence of smoking and comorbidities. Physical therapy was started on postoperative day 1 to recover range of motion (ROM) and ambulation with a walking aid and limited weight-bearing up to $20 \mathrm{~kg}$. The control receiver allowed $1 \mathrm{~mm}$ lengthening daily, divided into 3 sessions. During the distraction period (Figure 1) patients need close follow-up in the outpatient clinic, i.e., with 7-14 day intervals. Here, adequate bone formation was monitored with radiographs and range of motion was assessed at each visit. If necessary, the treatment plan could be adapted in order to prevent complications.

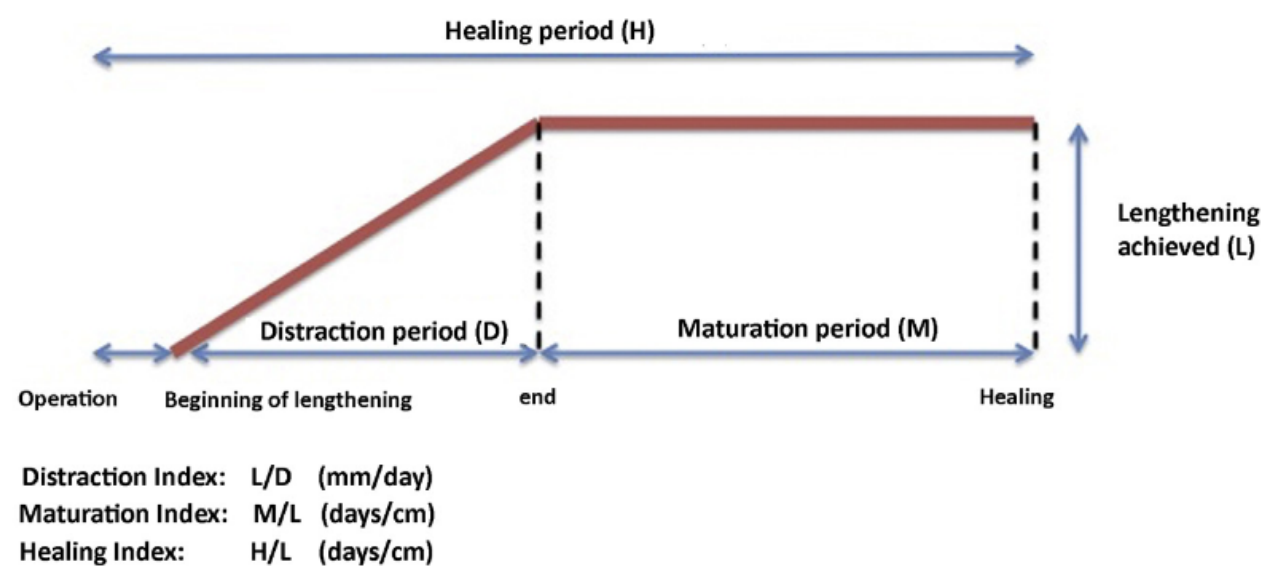

Figure 1. Lengthening phases and calculation of indices.

Compliance with daily physiotherapy is key in order to prevent loss of range of motion. If temporary loss of range of motion was noted during lengthening, daily physiotherapy sessions were increased. If we observe a loss of full extension or a temporary flexion contracture of the knee of more than 30 degrees, we paused the lengthening for 1 week in order to prevent subluxation and permanent joint contracture. The same protocol was applied if dorsiflexion of the ankle was reduced to 0 degrees or equinus. Moreover, we did not routinely prescribe orthoses, nor did we prophylactically lengthen tendons apart from the iliotibial band which was released in femoral lengthening of more than 3-4 cm.

During the maturation period, weight-bearing was resumed progressively. Full weightbearing was allowed once bone union was achieved, defined as at least 3 visible cortical bridges out of 4 cortices. All patients had a final clinical and radiographic follow-up six months after implant removal. 


\subsection{Lengthening Outcome Parameters}

The outcomes measured were the achieved lengthening, duration of the distraction phase (days), distraction index (days $/ \mathrm{cm})$, healing index (days $/ \mathrm{cm})$, length of hospital stay (days) (Figure 1), lower limb ROM at the latest follow-up, time to resume full weightbearing (days) and time to resume walking without aids (days).

The lengthening goal was achieved when it was within $5 \mathrm{~mm}$ of the initial plan. This corresponds to the LLD measurement error of long standing radiographs. Bone union was defined as at least 3 visible cortical bridges out of 4 in the regenerate on radiographic $\mathrm{AP}$ and lateral views. The pre- and postoperative mechanical axis deviation (MAD), mechanical lateral distal femoral angle (mLDFA) and medial proximal tibial angle (MPTA) were measured to assess alignment of the limb in the frontal plane. Intraoperative and postoperative complications were noted and categorized according to Paley's classification: problem (grade 1), obstacle (grade 2) and complication (grade 3) and according to Black in grade I, II, IIIA, IIIB [18,19].

\subsection{Statistical Analysis}

Statistical analysis was performed using Student's $t$ test (paired data: before limb lengthening surgery and at latest follow-up). Data are presented a mean \pm standard deviation. A $p$-value $\leq 0.05$ was considered statistically significant.

\section{Results}

A total of 34 patients with posttraumatic LLD and a mean age of $28.8 \pm 9.7$ years were included (Figure 2, Table 2). The mean LLD of $42.3 \pm 17.2 \mathrm{~mm}$, and a male/femaleratio of 2.7 (Table 2). The mean length of the hospital stay was $4.4 \pm 1.7$ days. Full weight-bearing and walking without aid resumed $139 \pm 52$ days and $226 \pm 133$ days after implantation, respectively.

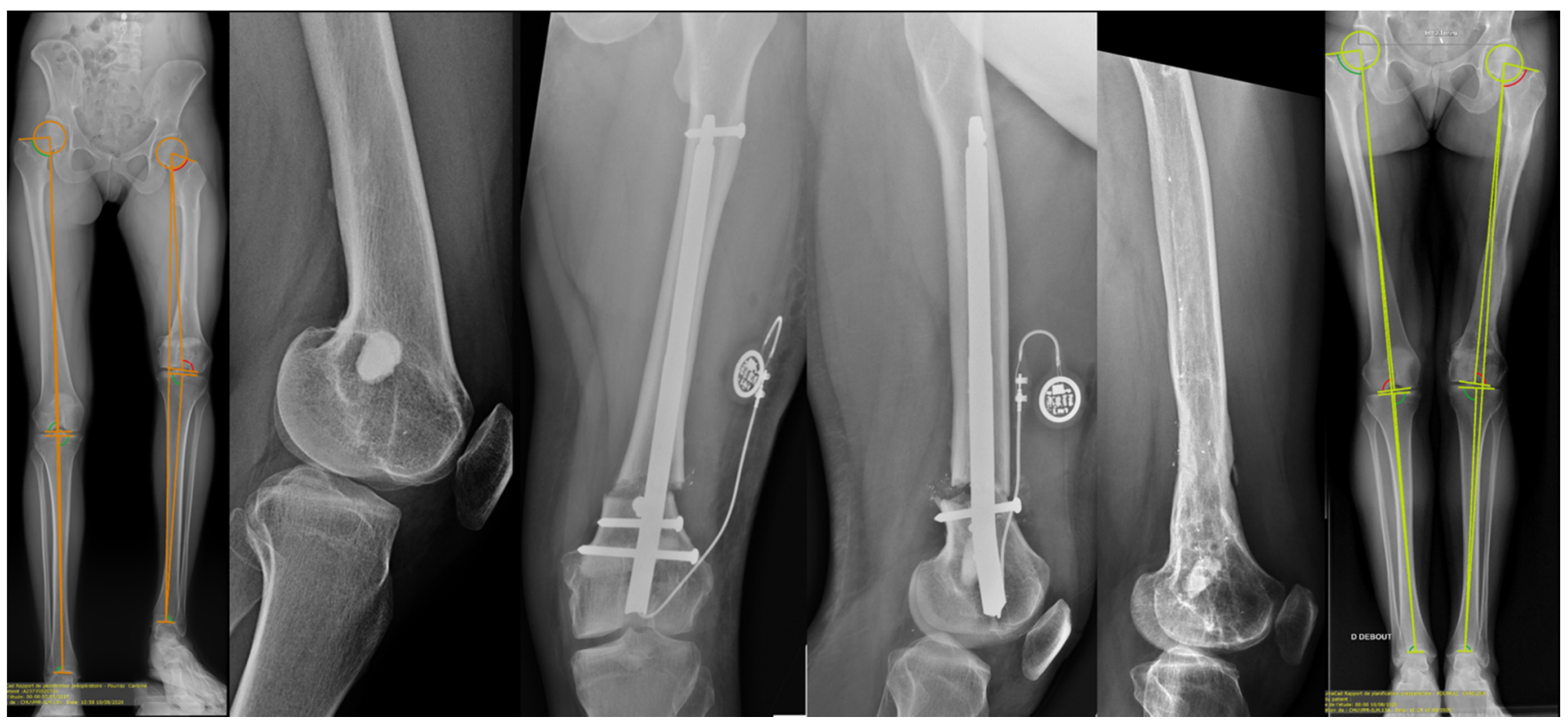

Figure 2. Radiographic images of a 26-year-old female with a $100 \mathrm{~mm}$ LLD associated with flexion and varus deformity due to growth plate injury at age 5 with subsequent attempted of Langenskiold procedure. $80 \mathrm{~mm}$ lengthening as well as correction in both the coronal and sagittal plane was performed with a retrograde FITBONE ${ }^{\circledR}$ TAA nail. 
Table 2. Demographics, injury, pre-existing complications, and outcomes: pre- and postlengthening LLD, mechanical axis, angles and complications of the 34 lengthened patients.

\begin{tabular}{|c|c|c|c|c|c|c|c|c|c|c|c|c|c|}
\hline ID & Gender & Age & Segment & & Injury & Initial Treatment & Previous Complications & $\begin{array}{l}\text { LLD } \\
(\mathrm{mm})\end{array}$ & $\begin{array}{l}\text { LLD } \\
(\mathrm{mm})\end{array}$ & $\begin{array}{l}\text { MAD } \\
(\mathrm{mm})\end{array}$ & $\begin{array}{c}\text { mLDFA } \\
\left({ }^{\circ}\right)\end{array}$ & $\underset{\left({ }^{\circ}\right)}{\operatorname{MPTA}}$ & Complications \\
\hline 1 & M & 30 & Femur & proximal & Trauma in childhood & dynamic hip screw & Coxa vara & 45 & 9 & & & & $\begin{array}{l}\text { Delayed union of } \\
\text { regenerate }\end{array}$ \\
\hline 2 & M & 13 & Femur & proximal & Unknown & cannulated screws & Coxa vara & 40 & 18 & 27 & 89 & 80 & Screw migration \\
\hline 3 & M & 28 & Femur & proximal & Motocross accident & dynamic hip screw & & 30 & 1 & 12 & 83 & 86 & $\begin{array}{l}\text { Hematoma, } \\
\text { lenothening delay }\end{array}$ \\
\hline $\begin{array}{l}4 \\
5\end{array}$ & $\begin{array}{l}M \\
M\end{array}$ & $\begin{array}{l}31 \\
36\end{array}$ & $\begin{array}{l}\text { Femur } \\
\text { Femur }\end{array}$ & $\begin{array}{l}\text { proximal } \\
\text { proximal }\end{array}$ & $\begin{array}{l}\text { Skiing accident } \\
\text { Fall from height }\end{array}$ & $\begin{array}{l}\text { trauma nail } \\
\text { trauma nail }\end{array}$ & Implant failure, osteoporosis & $\begin{array}{l}30 \\
27\end{array}$ & $\begin{array}{l}4 \\
4\end{array}$ & $\begin{array}{c}4 \\
12\end{array}$ & $\begin{array}{l}89 \\
88\end{array}$ & $\begin{array}{l}88 \\
85\end{array}$ & \\
\hline 6 & $\mathrm{~F}$ & 18 & Femur & shaft & Fall in childhood & ESIN & & 35 & 7 & 19 & 94 & 89 & $\begin{array}{l}\text { Receiver removal } \\
\text { (discomfort) }\end{array}$ \\
\hline 7 & M & 31 & Femur & shaft & Road traffic accident & trauma nail & Pseudarthrosis & 71 & 30 & 8 & 90 & 88 & \\
\hline 8 & M & 42 & Femur & shaft & $\begin{array}{l}\text { Road traffic } \\
\text { accident, motorcycle }\end{array}$ & trauma nail & Pseudarthrosis & 30 & 2 & 20 & 93 & 86 & \\
\hline 9 & $\mathrm{M}$ & 26 & Femur & shaft & Road traffic accident & trauma nail & Pseudarthrosis & 55 & 5 & 16 & 89 & 86 & Hematoma \\
\hline 10 & M & 35 & Femur & shaft & Work related accident & trauma nail & & 40 & 3 & 14 & 86 & 82 & $\begin{array}{l}\text { Hematoma, } \\
\text { lengthening delay }\end{array}$ \\
\hline 11 & M & 32 & Femur & shaft & $\begin{array}{c}\text { Road traffic } \\
\text { accident, motorcycle }\end{array}$ & trauma nail & & 40 & 10 & 1 & 94 & 96 & Hematoma \\
\hline 12 & M & 27 & Femur & shaft & Ballistic trauma & external fixation & $\begin{array}{l}\text { Arterial bypass due to femoral } \\
\text { ischemia, sepsis, angular } \\
\text { deformity, knee contracture }\end{array}$ & 80 & 7 & 40 & 96 & 84 & $\begin{array}{l}\text { Screw migration, } \\
\text { lengthening delay, } \\
\text { extreme knee } \\
\text { stiffness }\end{array}$ \\
\hline 14 & M & 53 & Femur & shaft & Fall from height & trauma nail & Angular deformity & 25 & 20 & 8 & 88 & 92 & Screw migration \\
\hline 15 & $\mathrm{M}$ & 19 & Femur & shaft & Motocross accident & trauma nail & Angular deformity & 45 & 11 & 25 & 91 & 86 & \\
\hline 16 & $\mathrm{M}$ & 27 & Femur & shaft & Trauma in childhood & tibial traction & Angular deformity & 50 & 6 & 13 & 95 & 95 & \\
\hline 17 & $\mathrm{~F}$ & 27 & Femur & shaft & Road traffic accident & trauma nail & & 30 & 5 & 8 & 89 & 85 & \\
\hline 18 & $\mathrm{~F}$ & 26 & Femur & shaft & $\begin{array}{l}\text { Road traffic } \\
\text { accident, motorcycle }\end{array}$ & ESIN & Angular deformity & 30 & 9 & 30 & 95 & 87 & \\
\hline 19 & M & 34 & Femur & distal & Road traffic accident & trauma nail & Pseudarthrosis & 24 & 3 & 6 & 86 & 86 & $\begin{array}{l}\text { Delayed union of } \\
\text { regenerate }\end{array}$ \\
\hline 20 & M & 28 & Femur & distal & $\begin{array}{c}\text { Road traffic } \\
\text { accident, motorcycle }\end{array}$ & plate & Knee contracture & 37 & 6 & 4 & 88 & 87 & Screw migration \\
\hline 21 & M & 27 & Femur & distal open & Ballistic trauma & external fixation & $\begin{array}{l}\text { Septic pseudarthrosis treated } \\
\text { with induced membrane } \\
\text { technique, plate failure, Judet's } \\
\text { quadricepsplasty, angular } \\
\text { deformity }\end{array}$ & 50 & 7 & 18 & 95 & 90 & $\begin{array}{l}\text { Screw migration, } \\
\text { lengthening delay, } \\
\text { implant failure }\end{array}$ \\
\hline
\end{tabular}


Table 2. Cont.

\begin{tabular}{|c|c|c|c|c|c|c|c|c|c|c|c|c|c|}
\hline ID & Gender & Age & Segmen & & Injury & Initial Treatment & Previous Complications & $\begin{array}{l}\text { LLD } \\
(\mathrm{mm})\end{array}$ & $\begin{array}{l}\text { LLD } \\
(\mathrm{mm})\end{array}$ & $\begin{array}{l}\text { MAD } \\
(\mathrm{mm})\end{array}$ & $\begin{array}{c}\text { mLDFA } \\
\left({ }^{\circ}\right)\end{array}$ & $\begin{array}{l}\text { MPTA } \\
\left({ }^{\circ}\right)\end{array}$ & Complications \\
\hline 22 & M & 22 & Femur & distal & Trauma in childhood & cast & $\begin{array}{c}\text { Fracture after lengthening with } \\
\text { external fixator, angular } \\
\text { deformity }\end{array}$ & 55 & 1 & & & & $\begin{array}{l}\text { Delayed union of } \\
\text { regenerate }\end{array}$ \\
\hline 23 & $\mathrm{~F}$ & 54 & Femur & distal & Trauma in childhood & cast & $\begin{array}{l}\text { Sepsis during lengthening with } \\
\text { external fixator, angular } \\
\text { deformity. }\end{array}$ & 70 & 40 & 19 & 86 & 80 & $\begin{array}{l}\text { Lengthening delay, } \\
\text { sepsis }\end{array}$ \\
\hline 24 & M & 17 & Femur & distal & $\begin{array}{l}\text { Road traffic } \\
\text { accident, motorcycle }\end{array}$ & trauma nail & & 25 & 2 & 8 & 89 & 84 & \\
\hline 25 & M & 17 & Femur & distal & Trauma in childhood & cannulated screws & & 40 & 17 & 17 & 89 & 84 & \\
\hline 26 & M & 14 & Femur & distal & Trauma in childhood & Kirschner wires & $\begin{array}{l}\text { Arterial bypass, sciatic palsy, } \\
\text { sepsis, skin graft }\end{array}$ & 50 & 14 & 15 & 91 & 95 & Knee contracture \\
\hline 27 & M & 39 & Femur & distal & $\begin{array}{c}\text { Road traffic } \\
\text { accident, motorcycle }\end{array}$ & plate & & 35 & 9 & 14 & 90 & 86 & $\begin{array}{l}\text { Hematoma, delayed } \\
\text { union of regenerate }\end{array}$ \\
\hline 28 & M & 39 & Femur & distal & $\begin{array}{c}\text { Road traffic } \\
\text { accident, motorcycle }\end{array}$ & plate & Angular deformity & 55 & 1 & 26 & 95 & 86 & $\begin{array}{l}\text { Delayed union of } \\
\text { regenerate, screw } \\
\text { migration }\end{array}$ \\
\hline 29 & $\mathrm{~F}$ & 26 & Femur & distal & Defenestration & unkown & Angular deformity & 100 & 2 & & & & $\begin{array}{l}\text { Hematoma } \\
\text { Hematoma }\end{array}$ \\
\hline 30 & $\mathrm{~F}$ & 26 & Pelvis & Tile type C & Riding accident & plate + screws & Loss of reduction & 22 & 1 & & & & $\begin{array}{l}\text { lengthening delay, } \\
\text { receiver removal } \\
\text { (discomfort) }\end{array}$ \\
\hline 31 & $\mathrm{~F}$ & 34 & Tibia & distal & $\begin{array}{c}\text { Road traffic } \\
\text { accident, motorcycle }\end{array}$ & $\begin{array}{l}\text { external fixation } \\
\text { antero-medial plate }\end{array}$ & & 30 & 4 & 3 & 86 & 86 & Hematoma \\
\hline 32 & $\mathrm{~F}$ & 14 & Tibia & distal & Trauma in childhood & Kirschner wires & Angular deformity & 29 & 7 & 10 & 86 & 89 & \\
\hline 33 & M & 24 & Tibia & open & $\begin{array}{l}\text { Road traffic } \\
\text { accident, pedestrian }\end{array}$ & trauma nail & & 45 & 19 & 19 & 84 & 93 & \\
\hline 34 & $\mathrm{~F}$ & 17 & Tibia & open & $\begin{array}{l}\text { Road traffic } \\
\text { accident, pedestrian }\end{array}$ & trauma nail & Angular deformity, skin graft & 25 & 5 & 15 & 88 & 83 & \\
\hline
\end{tabular}

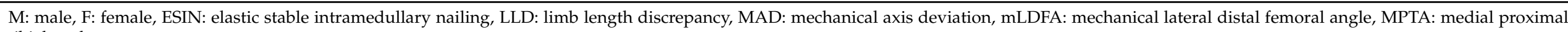
tibial angle. 
The approach for femoral lengthening was retrograde in 21 segments and antegrade in nine segments (Figure 2). Blocking screws were applied for 12/34 (35\%) lengthening surgeries (11 femurs and one tibia).

Mean lengthening was $37.5 \pm 19 \mathrm{~mm}$ for the femur and $23.7 \pm 7 \mathrm{~mm}$ for the tibia. A final LLD $\leq 5 \mathrm{~mm}$ was achieved in 12/34 patients, while $9 / 34$ patients had a final LLD of more than $10 \mathrm{~mm}$. Distraction stops were due to the development of ankle equinus, knee flexion contracture, infection of the surgical site, or interruption decided by the patient.

Mean distraction time was $60 \pm 27$ days and the mean distraction index was $0.59 \pm 0.16 \mathrm{~mm} /$ days. The mean healing index was $84.6 \pm 62.5$ days $/ \mathrm{cm}$ for the femur and $92.8 \pm 38.6$ days $/ \mathrm{cm}$ for the tibia.

Implant removal was performed at mean $19.7 \pm 7.7$ months after implantation. The mean follow-up time was $27.8 \pm 13.0$ months.

Coronal alignment: The mean mLDFA was $89.9^{\circ} \pm 6.1$ preoperatively and $90.1^{\circ} \pm 3.5$ postoperatively $(p=0.9)$. For cases without initial deformity, the mean postoperative mLDFA was $89.2^{\circ} \pm 3.2$ and was not statistically different from the contralateral side at $88^{\circ} \pm 2.3(p=0.15)$.

A subgroup of 10 patients with preoperative angular deformity in the frontal plane was analyzed. The mean postoperative mLDFA showed significant improvement from $95.7^{\circ} \pm 5$ preoperatively to $91.5^{\circ} \pm 3.4$ postoperatively $(p<0.01)$.

Knee ROM in the femoral group was considered satisfactory in 28 out of 30 cases. Mean flexion was unaltered, $125^{\circ} \pm 25$ vs. $128^{\circ} \pm 19(p=0.14)$. Two patients (gunshot wound and open floating knee injury) with limited preoperative ROM retained similar values after the surgery.

Postoperative complications were classified according to Paley and severity according to Black et al. [18,19].

There were 14/34 problems managed non-operatively:

- $\quad$ Eight hematomas at the osteotomy site that resolved spontaneously (severity I).

- Six lengthening delays relative to preoperative planning, which were offset by an increase in the number of daily distraction sessions (severity I).

There were 14/34 obstacles managed operatively:

- Six cases of locking screw migration, mostly occurring during the distraction phase, and revised with cemented screws (Figure 3, severity II).

- Two cases of subcutaneous receiver removal before nail extraction because of discomfort (severity II).

- One percutaneous hamstring tenotomy to treat a persistent $50^{\circ}$ knee flexion contracture in a patient with a $50 \mathrm{~mm}$ LLD. At the latest follow-up and after an intensive rehabilitation program, the flexion contracture had resolved (severity II).

- $\quad$ Five patients had delayed union among the femoral lengthening cases. Three of them had cancellous bone graft harvested from the anterior iliac crest; a short lateral approach was used to insert the graft after decortication of the site. This procedure was performed on average 14 months after implantation. The device had to be removed in one patient (nail breakage and malunion); treatment consisted of reaming and a trauma nail. Bone healing was achieved in all cases at the latest follow-up (severity II).

- One failure of the lengthening nail that was replaced 35 days after implantation with revision osteotomy. Lengthening proceeded satisfactorily thereafter with a final LLD of $7 \mathrm{~mm}$ (severity IIIA).

There were no intraoperative and 2/34 postoperative complications affecting the long-term outcome:

- $\quad$ One acute infection in a 54-year-old female patient with a $70 \mathrm{~mm}$ LLD associated with significant femur deformity and treated during childhood with monolateral external fixator. She was reoperated on postoperative day 10 with debridement and antibiotic therapy. Later on, deep vein thrombosis was found and treated with anticoagulant therapy. At the latest follow-up, the post lengthening LLD was $40 \mathrm{~mm}$ (severity IIIB). 
- One case of significant stiffness in a 27-year-old patient with an $80 \mathrm{~mm}$ LLD resulting from a gunshot injury with a flexion deficit. The patient underwent Judet's quadricepsplasty twice. The first resulted in a thrombosis of the femoral vascular graft and the second in an infection warranting surgical debridement and IV antibiotics. The limb was painful and non-functional at the last follow-up $\left(0 / 0 / 20^{\circ}\right.$ knee ROM) (severity IIIB).

Thus, in 34 segments we report $8+6=14$ severity grade I, $6+2+1+5+1=15$ severity grade II, 1 severity grade IIIA and 2 severity grade IIIB complications, including 26 unplanned surgeries.

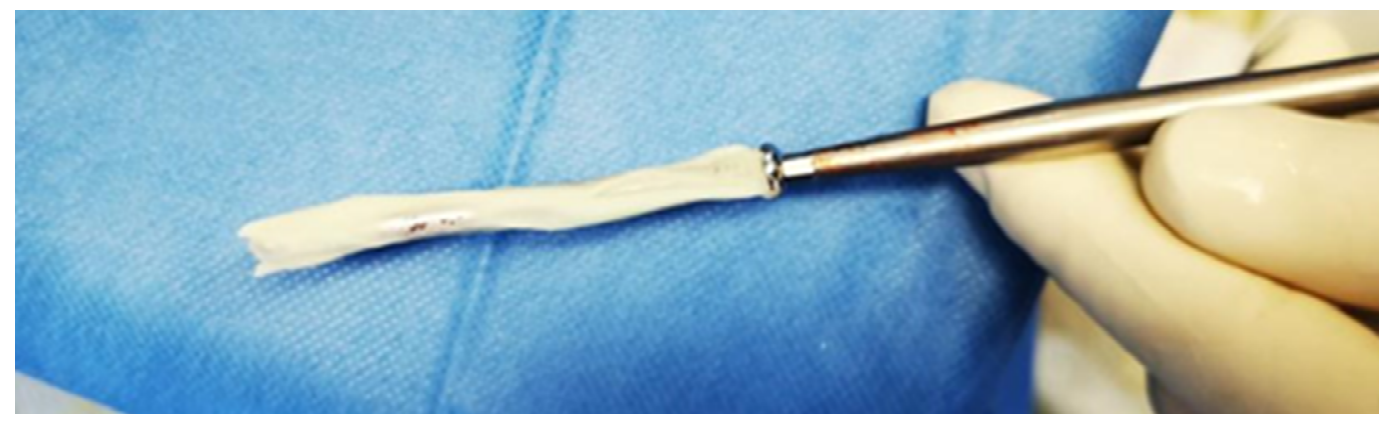

Figure 3. Revision of a migrating locking screw with bone cement coating. Coat the screw with regular bone cement, wait for 3-4 min before pushing and screwing it back into place. The tolerance between the screw $\varnothing 4.5 \mathrm{~mm}$, the drilled hole $\varnothing 4.5 \mathrm{~mm}$, and hole in the nail $\varnothing 4.6 \mathrm{~mm}$ ensures that no excessive cement remains within the bone. The cement acts as tight press-fitted mantle only. Most cement remains outside the lateral cortex and can be easily removed.

\section{Discussion}

Lengthening with the motorized Fitbone ${ }^{\circledR}$ nail is an acceptable and predictable solution to trauma-related LLD that can also be associated with axial and rotational deformity. The presented results are consistent with previous publications [7,11,20-23].

The percentage of patients who achieved the lengthening goals defined during preoperative planning $(45 \%)$ was lower than we had initially hoped for. Most of the cases where the targets were not achieved involved the largest LLD associated with complex deformities. The cases with a residual LLD of more than $1 \mathrm{~cm}$ at the last follow-up included several non-compliant patients who decided not to proceed until the end of the process of lengthening, one deep infection, and an equinus deformity after $40 \mathrm{~mm}$ tibial lengthening.

These findings underline the importance of patient selection. Careful preoperative evaluation of the motivation and the capacity of the patient to comply with the extensive and restrictive protocol (with daily lengthening sessions over several weeks, close followup during the distraction phase, intensive rehabilitation program, etc.) is key to increase the likelihood of good functional outcomes and minimize complications.

Any delays in the lengthening schedule were addressed with an increase in daily distraction sessions. These were likely caused by early bone consolidation, unauthorized weight-bearing, or non-compliance with the lengthening protocol.

The standard deviation of the mean femoral lengthening healing index was relatively wide ( $84.6 \pm 62.5)$ due to the presence of five delayed/insufficient consolidations that were surgically managed on average at 14 months after the implantation of the nail. All five bone segments were consolidated without affecting the long-term outcome. The healing index was measured independently. It is relatively high compared with the existing literature. The healing may have been negatively affected by previous damage to the fractured bone segment, its blood supply and soft tissue conditions. Moreover, some patients were active smokers who did not cease smoking despite our recommendation.

Thus, in 34 segments we report $41 \%$ severity grade I, $41 \%$ severity grade II, $2 \%$ severity grade IIIA and $5 \%$ severity grade IIIB complications [19,24]. There were more low-grade complications in this study compared to those found in the literature and similar high- 
grade complications rate. In comparison, Frost in their review of the literature found $11 \%$ of complication severity grade I, $15 \%$ grade II, $5 \%$ grade IIIA and $3 \%$ grade IIIB [20]. This may be due to the low-grade complications, such as transient postoperative hematoma, that are seldom reported in the literature. None of our patients had a redon drain inserted during surgery.

We report a total of 26 unplanned surgeries in 11/34 (32\%) of the segments. This high rate requires preoperative information of and consent to possible unplanned reoperation. Some of these reoperations were due to device-related complications. However, besides the recently reported adverse events of the latest generation of magnetically controlled limb lengthening nails, i.e., STRYDE, both FITBONE ${ }^{\circledR}$ and titanium PRECICE ${ }^{\circledR}$ have proven their clinical reliability and safety for many years [24-29]. Thaller et al. performed 241 FITBONE $^{\circledR}$ surgeries from 1999 until 2009 and imply that corrosion and osteolysis may also apply to a "number of FITBONE" [30]. Consequently, even though it was not the primary objective of the present study, we evaluated the latest radiographs and found no osteolysis and no periosteal reaction at the telescoping junction in our prospective cohort of 34 patients that were operated from 2010 until 2019. Moreover, we did not observe a significant amount of corrosion on the retrieved FITBONE ${ }^{\circledR}$ nails, which were returned to Wittenstein intens ( $\mathrm{GmbH}$, Ingersheim, Germany) as part of the company's routine quality control.

The relatively high reoperation rate in our series may partially be explained by the fact that multiple of our cases were polytrauma patients with comorbidities that could lead to complications, such as complex osseous injuries (deformity, osteoporosis due to limited weight bearing, non-union, osteomyelitis), the presence of fixation devices (broken implant, difficult extraction), as well as musculoskeletal (joint stiffness, muscle atrophy) and cutaneous disorders (scarring after open fracture, skin graft, scarring from prior surgery) [31,32]. Multidisciplinary management by the surgeon, rehabilitation specialists, infectious diseases specialist, and paramedical team is needed in such cases. We encountered no fractures of the regenerated bone or any failure due to the intramedullary nail having weakened the cortical bone.

Besides restoring limb length, the majority of associated angular and rotational deformities can also be managed using intramedullary lengthening nails. In this regard, the finding of the present study is in line with the existing literature [12,13,16,20,32-36]. However, in comparison with external fixators allowing gradual correction, correction of these deformities with intramedullary devices limits the postoperative options for correcting the mechanical axes of the limb. Therefore, a high degree of planning and intraoperative accuracy are essential [13,33-36]. The application of blocking screws is often needed to achieve and maintain the pre-operative plan. Sharp and rigid reamers can help to overcome potential posttraumatic challenges such as an obliterated intramedullary canal and thus help to restore limb alignment. We used this technique to position the nail in coronal deformity cases and, in our opinion, it should be more widely indicated. Indeed, it improves construct stability and nail alignment, especially in the distal femoral metaphysis. Furthermore, less stress on the locking screws theoretically reduces the risk of locking screw migration/pull-out. There were six cases of locking screw migration, which was the most common cause of revision surgery in our cohort. Other authors also report this complication $[18,20]$. The lack of screw threads in the far cortex and in the cancellous bone in the distal femoral metaphysis is likely to contribute to this phenomenon.

This study has several limitations. First, the studied cohort was relatively small (34 patients) and heterogenous in the causes of posttraumatic LLD. Secondly, deformity correction was only assessed for varus deformities of the femur. Thirdly, this study neither assessed patient satisfaction nor daily, physical and social activities.

\section{Conclusions}

In conclusion, bone lengthening with a motorized intramedullary nail system for posttraumatic LLD is a reliable treatment modality. The risk of serious complications and 
sequelae is relatively low in compliant and motivated patients. Limb length and axes can be restored with proper preoperative planning and meticulous surgery.

Author Contributions: Conceptualization, J.S.d.G., J.D.R. and F.A.; methodology, J.S.d.G., J.D.R. and F.A.; surgery, F.A.; analyses, M.T., T.L. and F.A.; resources, J.S.d.G. and F.A.; data curation, M.T., T.L. and J.D.R.; writing—original draft preparation, M.T., T.L., J.D.R. and F.A.; writing—review and editing, all authors; supervision, J.S.d.G. and F.A. All authors have read and agreed to the published version of the manuscript.

Funding: This research received no external funding.

Institutional Review Board Statement: The study was conducted according to the guidelines of the Declaration of Helsinki and approved by the Internal Review Board of Toulouse University Hospital on 10 December 2009, approval number: 02-1209.

Informed Consent Statement: Informed written consent was obtained from all patients involved in the study regarding participation and publication.

Data Availability Statement: The data presented in this study are available on request from the corresponding author. The data are not publicly available because the patients did not provide their written consent. If data are shared and used in other non-profit publications, this paper must be cited.

Conflicts of Interest: F.A. and J.D.R. are a paid consultants for Orthofix Academy. The remaining authors declare no conflict of interest. This study was entirely financed by public funds. No external funding was required.

\section{References}

1. Winquist, R.A.; Hansen, S.T.; Clawson, D.K. Closed intramedullary nailing of femoral fractures. A report of five hundred and twenty cases. J. Bone Joint Surg. Am. 1984, 66, 529-539. [CrossRef]

2. Vaidya, R.; Anderson, B.; Elbanna, A.; Colen, R.; Hoard, D.; Sethi, A. CT scanogram for limb length discrepancy in comminuted femoral shaft fractures following IM nailing. Injury 2012, 43, 1176-1181. [CrossRef]

3. Ricci, W.M.; Gallagher, B.; Haidukewych, G.J. Intramedullary nailing of femoral shaft fractures: Current concepts. J. Am. Acad. Orthop. Surg. 2009, 17, 296-305. [CrossRef]

4. Herscovici, D.; Scaduto, J.M. Assessing leg length after fixation of comminuted femur fractures. Clin. Orthop. Relat. Res. 2014, 472, 2745-2750. [CrossRef]

5. Lombardo, S.J.; Harvey, J.P. Fractures of the distal femoral epiphyses. Factors influencing prognosis: A review of thirty-four cases. J. Bone Joint Surg. Am. 1977, 59, 742-751. [CrossRef]

6. Arkader, A.; Warner, W.C.; Horn, B.D.; Shaw, R.N.; Wells, L. Predicting the outcome of physeal fractures of the distal femur. J. Pediatric Orthop. 2007, 27, 703-708. [CrossRef]

7. Axelrod, D.; Rubinger, L.; Shah, A.; Guy, P.; Johal, H. How should we lengthen post-traumatic limb defects? A systematic review and comparison of motorized lengthening systems, combined internal and external fixation and external fixation alone. Eur. J. Orthop. Surg. Traumatol. 2020. [CrossRef]

8. Singh, S.; Lahiri, A.; Iqbal, M. The results of limb lengthening by callus distraction using an extending intramedullary nail (Fitbone) in non-traumatic disorders. J. Bone Joint Surg. Br. Vol. 2006, 88, 938-942. [CrossRef]

9. Gordon, J.E.; Manske, M.C.; Lewis, T.R.; O’Donnell, J.C.; Schoenecker, P.L.; Keeler, K.A. Femoral Lengthening Over a Pediatric Femoral Nail: Results and Complications. J. Pediatric Orthop. 2013, 33, 730-736. [CrossRef]

10. Horn, J.; Grimsrud, Ø.; Dagsgard, A.H.; Huhnstock, S.; Steen, H. Femoral lengthening with a motorized intramedullary nail: A matched-pair comparison with external ring fixator lengthening in 30 cases. Acta Orthop. 2015, 86, 248-256. [CrossRef]

11. AL-Sayyad, M.J. Lower limb lengthening and deformity correction using the Fitbone motorized nail system in the adolescent patient. J. Pediatric Orthop. B 2012, 21, 131-136. [CrossRef]

12. Accadbled, F.; Pailhé, R.; Cavaignac, E.; Sales de Gauzy, J. Bone lengthening using the Fitbone ${ }^{\circledR}$ motorized intramedullary nail: The first experience in France. Orthop. Traumatol. Surg. Res. 2016, 102, 217-222. [CrossRef]

13. Baumgart, R. The reverse planning method for lengthening of the lower limb using a straight intramedullary nail with or without deformity correction: A new method. Orthop. Traumatol. 2009, 21, 221-233. [CrossRef] [PubMed]

14. Krettek, C.; Stephan, C.; Schandelmaier, P.; Richter, M.; Pape, H.C.; Miclau, T. The use of Poller screws as blocking screws in stabilising tibial fractures treated with small diameter intramedullary nails. J. Bone Joint Surg. Br. Vol. 1999, 81, 963-968. [CrossRef]

15. Rozbruch, S.R.; Fragomen, A.T.; Muthusamy, S. The use of blocking screws with internal lengthening nail and reverse rule of thumb for blocking screws in limb lengthening and deformity correction surgery. Strateg. Trauma Limb Reconstr. 2016, 11, 199-205. [CrossRef]

16. Rozbruch, S.R. Adult posttraumatic reconstruction using a magnetic internal lengthening nail. J. Orthop. Trauma 2017, 31 (Suppl. 6), S14. [CrossRef] [PubMed] 
17. Herzenberg, J.E.; Paley, D. Principles of Deformity Correction; Springer: Berlin/Heidelberg, Germany, 2014.

18. Paley, D. Problems, obstacles, and complications of limb lengthening by the Ilizarov Technique. Clin. Orthop. Relat. Res. 1990, 81, 104. [CrossRef]

19. Black, S.R.; Kwon, M.S.; Cherkashin, A.M.; Samchukov, M.L.; Birch, J.G.; Jo, C.H. Lengthening in congenital femoral deficiency: A comparison of circular external fixation and a motorized intramedullary nail. J. Bone Joint Surg. Am. Vol. 2015, 97, 1432-1440. [CrossRef]

20. Horn, J.; Hvid, I.; Huhnstock, S.; Breen, A.B.; Steen, H. Limb lengthening and deformity correction with externally controlled motorized intramedullary nails: Evaluation of 50 consecutive lengthenings. Acta Orthop. 2019, 90, 81-87. [CrossRef] [PubMed]

21. Alrabai, H.M.; Gesheff, M.G.; Conway, J.D. Use of internal lengthening nails in post-traumatic sequelae. Int. Orthop. 2017, 41, 1915-1923. [CrossRef]

22. Hammouda, A.I.; Jauregui, J.J.; Gesheff, M.G.; Standard, S.C.; Conway, J.D.; Herzenberg, J.E. Treatment of post-traumatic femoral discrepancy with PRECICE magnetic-powered intramedullary lengthening nails. J. Orthop. Trauma 2017, 31, 369-374. [CrossRef]

23. Krieg, A.H.; Lenze, U.; Speth, B.M.; Hasler, C.C. Intramedullary leg lengthening with a motorized nail: Indications, challenges, and outcome in 32 patients. Acta Orthop. 2011, 82, 344-350. [CrossRef]

24. Frost, M.W.; Rahbek, O.; Traerup, J.; Ceccotti, A.A.; Kold, S. Systematic review of complications with externally controlled motorized intramedullary bone lengthening nails (FITBONE and PRECICE) in 983 segments. Acta Orthop. 2021, 92, 120-127. [CrossRef] [PubMed]

25. Rölfing, J.D.; Kold, S.; Nygaard, T.; Mikuzis, M.; Brix, M.; Faergermann, C.; Gottliebsen, M.; Davidsen, M.; Petruskevicius, J.; Olesen, U.K. Pain, osteolysis, and periosteal reaction are associated with the STRYDE limb lengthening nail: A nationwide cross-sectional study. Acta Orthop. 2021. [CrossRef] [PubMed]

26. Jellesen, M.S.; Lomholt, T.N.; Hansen, R.Q.; Mathiesen, T.; Gundlach, C.; Kold, S.; Nygaard, T.; Mikuzis, M.; Olesen, U.K. The STRYDE limb lengthening nail is susceptible to mechanically assisted crevice corrosion-An analysis of 23 retrieved implants. Acta Orthop. 2021. [CrossRef]

27. Iliadis, A.D.; Wright, J.; Stoddart, M.T.; Goodier, W.D.; Calder, P. Early results from a single centre's experience with the STRYDE nail. Bone Joint J. 2021. [CrossRef]

28. Frommer, A.; Rödl, R.; Gosheger, G.; Schulze, M.; Hasselmann, J.; Fuest, C.; Toporowski, G.; Laufer, A.; Vogt, B. Focal osteolysis and corrosion at the junction of Precice Stryde intramedullary lengthening device-Preliminary clinical, radiographic and metallurgic analysis of 57 lengthened segments. Bone Joint Res. 2021. (under review/personal communication).

29. Rölfing, J.D.; Bünger, M.; Petruskevicius, J.; Abood, A. Removal of broken PRECICE Stryde limb lengthening nails. Orthop. Traumatol. Surg. Res. 2021. [CrossRef] [PubMed]

30. Thaller, P.H.; Frankenberg, F.; Degen, N.; Soo, C.; Wolf, F.; Euler, E.; Fürmetz, J. Complications and effectiveness of intramedullary limb lengthening: A matched pair analysis of two different lengthening nails. Strateg. Trauma Limb Reconstr. 2020, 15, 7-12.

31. Zura, R.; Xiong, Z.; Einhorn, T.; Watson, J.T.; Ostrum, R.F.; Prayson, M.J.; Della Rocca, G.J.; Mehta, S.; McKinley, T.; Wang, Z.; et al. Epidemiology of fracture nonunion in 18 human bones. JAMA Surg. 2016, 151, e162775. [CrossRef]

32. Krettek, C.; Mommsen, P. Implant removal after intramedullary osteosyntheses. Literature review, technical details, and tips and tricks. Unfallchirurg 2012, 115, 299-314. [CrossRef]

33. Küçükkaya, M.; Karakoyun, Ö.; Sökücü, S.; Soydan, R. Femoral lengthening and deformity correction using the Fitbone motorized lengthening nail. J. Orthop. Sci. 2015, 20, 149-154. [CrossRef] [PubMed]

34. Iobst, C.A.; Rozbruch, S.R.; Nelson, S.; Fragomen, A. Simultaneous acute femoral deformity correction and gradual limb lengthening using a retrograde femoral nail: Technique and clinical results. J. Am. Acad. Orthop. Surg. 2018, 26, 241-250. [CrossRef] [PubMed]

35. Fragomen, A.T.; Rozbruch, S.R. Lengthening and deformity correction about the knee using a magnetic internal lengthening nail. SICOT J 2017, 3, 25. [CrossRef] [PubMed]

36. Abood, A.; Petruskevicius, P.; Vogt, B.; Frommer, A.; Rödl, R.; Rölfing, J.D. The Joint Angle Tool for intraoperative assessment of coronal alignment of the lower limb. Strateg. Trauma Limb Reconstr. 2020, 15, 169-173. [CrossRef] 